I.A.A.R.C.

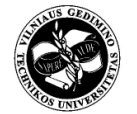

Institute of Internet and Intelligent Technologies

Vilnius Gediminas Technical University

Saulètekio al. 11, 10223 Vilnius, Lithuania

http://www.isarc2008.vgtu.lt'
The $25^{\text {th }}$ International Symposium on Automation and Robotics in Construction

June 26-29, 2008

ISARC-2008

\title{
BENCHMARKING FOR CONSTRUCTION MANAGEMENT PROCESS REENGINEERING
}

\author{
Min-Yuan Cheng \\ Professor, Dept. of Construction \\ Engineering, National Taiwan \\ University of Science and \\ Technology. \\ Address: \#43, Sec. 4, Keelung \\ Rd., Taipei, Taiwan, R.O.C. 106, \\ myc@mial.ntust.edu.tw
}

\author{
Ming-Hsiu Tsai \\ Assistant Professor, Dept. of \\ Civil Engineering, TamKang \\ University \\ 151 Ying-chuan Road, Tamsui, \\ Taipei, Taiwan, R.O.C. 25137 \\ mht@mail.tku.edu.tw
}

\author{
Wiraputra Sutan \\ Graduate Student, Dept. of \\ Construction Engineering, \\ National Taiwan University \\ of Science and Technology. \\ Address: \#43, Sec. 4, Keelung \\ Rd., Taipei, Taiwan, R.O.C. 106 \\ M9405807@mail.ntust.edu.tw
}

\begin{abstract}
Benchmarking philosophy was applied to construction management process reengineering so that process managers can reengineer processes by learning the best-practice company's process. For this purpose, this paper addressed the process adaptability evaluation method to assist managers determining the best-to-learn process from the best-practice companies. By using the proposed method, the Adaptability Index $(A I)$ can be calculated to represent the acceptance degree of each best-practice process. Not only the process similarity but also the process communication ease was considered as the primary factors to evaluate the $A I$ value. The higher the $A I$ is, the more suitable the process is. Accordingly, the project team can determine the best-to-learn process in accordance with the evaluated $A I$ value.
\end{abstract}

\section{KEYWORDS}

construction management process, reengineering, benchmarking, process similarity, trend model.

\section{INSTRUCTIONS}

The phrase "business process reengineering" (BPR) first appeared in 1990 which attempts to achieve dramatic improvements in critical measures of performance by using the power of current information technology (IT) to rethink and redesign the business process fundamentally and radically[1]. Referring to the original BPR philosophy, the construction management process reengineering (CMPR) model was addressed by Cheng and Tsai [2] to reengineer the critical processes of construction companies. However, not only redesigning a process in a manner that relies upon a trial and error approach may be time consuming due to lack of data and experience, but also the effectiveness of the newly redesigned process' cannot be insured because validation work can begin only after implementation, process reengineering is treated as a high risk solution to business performance enhancement. Accordingly, if a construction company can redesign its processes based on the 
best-practice companies' process, the risk and duration of process reengineering project may be decreased. Following this idea, a method applying the benchmarking philosophy to construction management process reengineering was proposed in this paper. Process managers can redesign processes by learning the best-practice process best suited to benchmarking companies[3][4].

Therefore, this study focuses on determining the most suitable best-practice processes for a benchmarking construction company. The most suitable processes that would be learned by the benchmarking company are defined as those with characteristics similar to the reengineered process, which should be implemented most smoothly in the benchmarking company. That is, the process similarity and the degree of communication ease are two factors of best-practice processes needing to be evaluated. The higher process similarity is, the more similar functions and information items the compared processes have, and lower degree of communication ease the best-practice process has, the more smoothly it would be implemented in the benchmarking company. Accordingly, a conceptual idea of process adaptability evaluation method integrating the semantic similarity and the trend model methodologies to determine the process similarity and communication ease of best-practice processes respectively was proposed in this paper.

The process adaptability evaluation method was developed including process similarities analysis, and process communication index analysis. On the one hand process similarities analysis is an approach applying the concepts of semantic similarities analysis to find the semantic-related objects between bestpractice processes and benchmarking process, on the other hand process communication index analysis developed based on the trend model concept was applied to evaluate the degree of communication ease for best-practice processes once such are implemented in the benchmarking company.

Summarily, to assist a process reengineering project team to redesign a process based on the most suitable best-practice process, this research proposed a process reengineering method combining with the benchmarking philosophy. The concept of the process adaptability evaluation method was addressed as followings.

\section{CONCEPTUAL ARCHITECTURE OF PROCESS ADAPTABILITY EVALUATION METHOD}

The process adaptability evaluation method encompasses four analysis phases; namely, (1) business process modeling, (2) process similarities analysis, (3) process communication index analysis, and (4) process adaptability calculation as shown in Figure 1. In the business process modeling phase, a process model providing formal representation of characteristics of process from the best-practice company and benchmarking company is necessarily constructed to be the model analyzed. Subsequently, the process semantic similarities can be calculated during the process similarity analysis. Then, the degree of communication eases of best-practice process to be performed in benchmarking company is evaluated by process communication analysis. Finally, an adaptability index that represents the acceptance degrees of each best-practice process for benchmarking company can be summarized in the last phase.

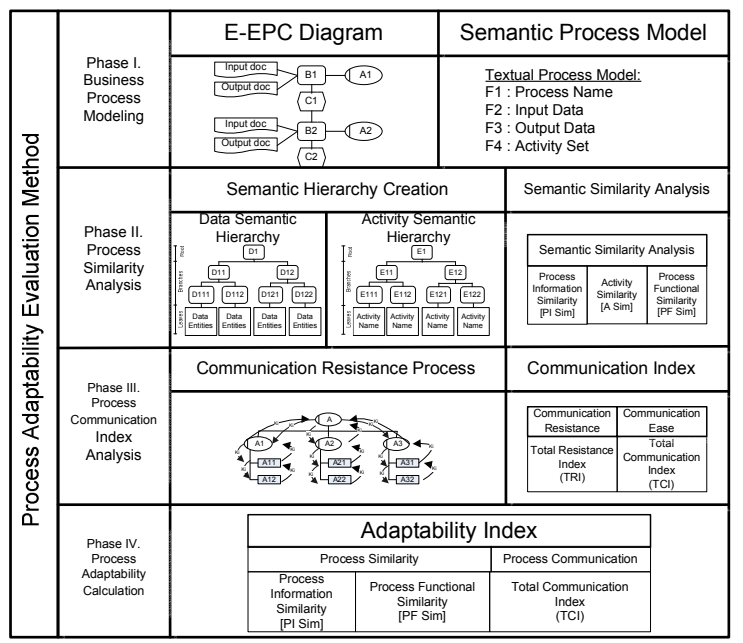

Figure 1. Architecture of Process Adaptability Evaluation

Phase I. Business Process Modeling: a process model providing formal representation of characteristics of processes is necessarily 
constructed from the beginning of process reengineering. Two process models need to be created, namely, (1) graphic process model, and (2) textual process model, for the next anslysis steps. The graphic process model is represented with eEPC diagram of ARIS modeling language [5]. The textual process model is mapped from graphic model into four subsets, namely, f1:\{process name\}, f2: \{process input data\}, 3 \{process output data\} and $\mathrm{f} 4$ \{activity set\} [6]. Meanwhile, each activity set is also composed of its name, input and output subsets. Based on the characteristics within the created models, the process similarities and degree of communication ease can then be evaluated.

Phase II. Process Similarity Analysis [6]: Process similarity is one of the important factors to be considered in this paper. Process similarity represents the corresponding relationship of data and activities between benchmarking company and bestpractice company. The higher similarities of the processes have, the more similar the characteristics are. For the purpose, this study applies semantic similarity analysis to evaluate process information similarity (PISim) and process function similarity (PFSim) between benchmarking company process and best-practice company process. Therefore, a semantic hierarchy corresponding to the process models is created to depict the concept relationships of data and of activities entities, so that the semantic distance between two entities can be identified, and their semantic affinity can then be calculated. Consequently, two parameters, namely, name affinity and name set affinity, are applied to evaluate process similarity.

Phase III. Process Communication Index Analysis: Process communication index analysis emphasizes on organization view of a process and the main purpose is to evaluate the degree of communication ease of best-practice processes into benchmarking company organization structure so that the success of BPR implementation might be increased. By applying a trend model methodology, the degree of communication ease is evaluated. In this phase, a questionnaire survey was objectively conducted using the AHP method to obtain the resistance coefficient $(K i)$ of a process based on benchmarking organization structure [7]. The resistance coefficient $(K i)$ is used to evaluate the ease of communication for solving disputes, conflicts, or coordination problems between related parties in different layers. Based on the resistance coefficient $(K i)$, a Total Resistance Index (TRI) and Total Communication Index $(T C I)$ are analyzed.

Phase IV. Process Adaptability Calculation: Process adaptability calculation summarized by process similarity analysis and process communication index analysis. The purpose of process adaptability calculation is to create an adaptability index that represents the acceptance degrees of best-practice processes for benchmarking company.

Following the concept of process adaptability evaluation method, the most suitable best-practice process can be determined in accordance with not only the similar features but also the degree of communication ease of the evaluated processes, i.e. the process similarity and the process communication index are two most primary characteristics of best-practice processes necessary to be evaluated.

\section{PROCESS SIMILARITY INDEX}

The purpose of process similarity index is to illustrate the commonalities between the benchmarking process and best-practice processes. In this paper, the degrees of process information similarity (PISim) and process functional similarity (PFSim) were proposed to respectively present the similar information characteristics and functions between processes. For this purpose, this study followed the semantic similarity analysis methodology addressed by Cheng and Tsai [6] to evaluate PISim and PFSim between benchmarking company and best-practice company processes.

\section{Process Information Similarity}

The process information similarity denoted by $\operatorname{PISim}\left(P_{i}, P_{j}\right)$ is the measure of similarity of input and output information sets corresponding to two analyzed processes $P_{i}$ and $P_{j}$. Equation (1) shows the conceptual function of process information similarity. 


$$
\operatorname{PISim}\left(P_{i}, P_{j}\right)=\sum_{f \in \zeta} A\left(P_{i} \cdot f, P_{j} \cdot f\right)
$$

where $A()$ is the affinity function of two entities; the $\mathrm{P}_{\mathrm{i}}$ and $\mathrm{P}_{\mathrm{j}}$ are respectively the semantic process model of process $\mathrm{i}$ and of process $\mathrm{j} ; \zeta=\left\{\mathrm{f}_{\mathrm{in}}, \mathrm{f}_{\mathrm{out}} \mid \mathrm{f}_{\mathrm{in}}=\right.$ $\operatorname{INPUT}\left(\mathrm{P}_{\mathrm{k}}\right)$ of $\mathrm{P}_{\mathrm{k}}, \mathrm{f}_{\text {out }}=\operatorname{OUTPUT}\left(\mathrm{P}_{\mathrm{k}}\right)$ of $\left.\mathrm{D}_{\mathrm{k}}\right\}$, and 0 $\leqq \operatorname{PISim}\left(\mathrm{P}_{\mathrm{i}}, \mathrm{P}_{\mathrm{j}}\right) \leqq 2$.

To calculate the PISim of $P i$ and $P j$ processes, the created process models in the phase $I$ need the capability presenting the input and output information sets of the modelled processes.

\section{Process Functional Similarity}

The process functional similarity denoted by $\operatorname{PFSim}\left(P_{i}, P_{j}\right)$ is the measure of similarity of functional activities respectively within two analyzed processes $P_{i}$ and $P_{j}$. For calculating the $\operatorname{PFSim}\left(P_{i}, P_{j}\right)$ value, a microcosmic view form activities of processes is necessary to conduct advanced similarity analysis. Equation (2) expresses the activity similarity function denoted by $A \operatorname{Sim}\left(A_{h i}, A_{k j}\right)$.

$$
\begin{aligned}
\operatorname{ASim}\left(A_{i h}, A_{j k}\right)= & N A\left(A_{i h}, A_{j k}\right)+A\left(A I N_{i h}, A I N_{j k}\right) \\
& +A\left(A O U T_{i h}, A O U T_{j k}\right)
\end{aligned}
$$

where $N A()$ is the name affinity function of tow names; the $A_{i h}$ is the name of $h^{\text {th }}$ activity of the process $i ; A_{j k}$ is the name of $k^{\text {th }}$ activity of the process $j ; A \operatorname{Sim}\left(A_{i h}, A_{j k}\right)$ is activity similarity of $A_{i h}$ and $A_{j k} ; A I N_{i h}$ is the input set of $A_{h i} ; A O U T_{j k}$ is the output set of $A_{j k}$, and $0 \leqq A \operatorname{Sim}\left(A_{i h}, A_{j k}\right) \leqq 3$.

In Equation (2), not only information similarity, expressed by $A\left(A I N_{i h}, A I N_{j k}\right)$ and $A\left(A O U T_{i h}\right.$, $\left.A O U T_{j k}\right)$ ), but functional similarity, expressed by $N A\left(A_{i h}, A_{j k}\right)$, is of concern. High activity similarity expresses the idea that two activities are similar in terms of work tasks. Thus, by summarizing the $A\left(A I N_{i h}, A I N_{j k}\right)$ values as shown in Equation (3), the Process Functional Similarity of $P_{i}$ and $P_{j}$, denoted by $P F \operatorname{sim}\left(P_{i}, P_{j}\right)$, can be calculated. Similar to PISim(), a higher PFSim value indicates a greater degree of similarity between the activities of two discrete processes.

$$
\begin{aligned}
& \operatorname{PFSim}\left(P_{i}, P_{j}\right)= \\
& \frac{\sum_{h=1}^{m} \operatorname{Max}_{k=1 \rightarrow n}\left(\operatorname{ASim}\left(A_{i h}, A_{j k}\right)+\sum_{k=1}^{n} \operatorname{Max}_{h=1 \rightarrow m}\left(\operatorname{ASim}\left(A_{i h}, A_{j k}\right)\right.\right.}{m+n} \\
& \text { where } \forall A_{i h} \in P_{i} ; \forall A_{j k} \in P_{j}
\end{aligned}
$$

\section{PROCESS COMMUNICATION INDEX}

The primary purpose of process communication index analysis is to evaluate the degree of communication ease from best-practice processes that occur within the benchmarking organization structure. The total communication index $(T C I)$ is proposed in this paper to express the degree of communication ease exhibited by best-practice processes. The higher the communication index of best-practice process, the smoother the best-practice process can be adopted by the benchmarking company. To evaluate the communication index, the concept of trend model methodology was applied in this paper.

The trend model methodology [7] proposed a proper method to evaluate the communication resistance of a process within organization. High process resistance implies low degree of communication ease of a process. Accordingly, the TCI of a process can be determined in accordance with the process resistance value evaluated by the trend model method. Following this idea, a TCI evaluation procedure including five steps; namely, (1) plotting process network, (2) establishment of activity relationship matrix $(A R M)$, (3) developing organizational structure's communication resistance matrix $(C R M)$, (4) calculating total resistance index (TRI) of the best-practice process, and (5) Calculation of total communication index $(T C I)$ is proposed in this paper.

With the application of the trend model, the process network that represents best-practice processes with the benchmarking department units is created firstly. Subsequently, the activity relationship matrix (ARM) is developed to show the sequential activity relationship between benchmarking department units in best-practice processes. According to the result of the $A R M$, a communication resistance matrix (CRM) is generated to calculate the resistance values between benchmarking department units. Moreover, 
the total resistance index (TRI) of best-practice processes when it is performed in benchmarking company is calculated. Finally, by converting the result of total resistance index (TRI), the total communication index $(T C I)$ can be calculated to show the total communication ease of benchmarking organizational structure referring to best-practice processes. Based on the TCI resulted values from the aforementioned procedures, the best-practice process which can be executed most smoothly when it is adapted in benchmarking company can be determined.

\subsection{Plotting Process Network}

The first step toward developing process communication analysis is to create a process network that describes the activity elements of a process in a logical hierarchy. Moreover, to evaluate the resistance values of best-practice processes operated in the benchmarking company, the department unit in the original best-practice process model must be replaced by the benchmarking department unit; i.e. the analyser needs to assign department units according to the organization structure of the benchmarking company to the activities within the best-practice process model. Accordingly, based on the modified best-practice process model, the TRI value of the best-practice process can then be evaluated.

\subsection{TRI Evaluation for Best-Practice Process}

Based on the Trend Model methodology, the department communication frequency and the resistance coefficients between departments within an organization structure are necessary for bestpractice process TRI evaluation. The product of the department communication frequency and the resistance coefficient presents the total resistant value of a best-practice process. According to this concept, the activity relationship matrix $(A R M)$, and the organizational structure's communication resistance matrix $(C R M)$ are proposed for $T R I$ calculation in this paper.

Activity Relationship Matrix (ARM): the establishment of the $A R M$ is to show the communication frequency between the departments as all activities of a process were performed. Figure
2 shows an example of ARM derived from the procurement process of a case study. The values in cells present the communication times from the department unit related to preceding activities to those related to succeeding activities within the evaluated process.

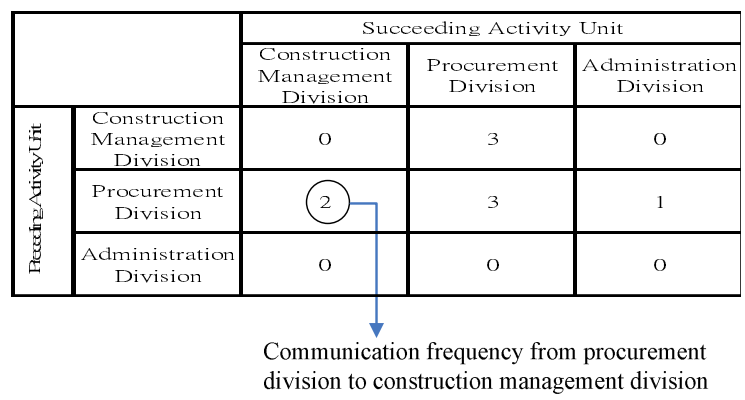

Figure 2. Example of Activity Relationship Matrix

Communication Resistance Matrix (CRM): the $\mathrm{CRM}$, represents as $K i$, comprises communication resistance values between two departments of different layers within an organizational structure. Resistance coefficient $K i$ is the basic variable used to represent the degree of communication ease in a project. Figure 3 shows communication resistance of the benchmarking organization structure related to the procurement process. The values of $K i$, was surveyed via a questionnaire for division managers of the benchmarking company. In Figure 3 , the process communication is assumed to be transferred through the layer structures. Therefore, messages passed from the head of the Engineering Department to the head of the Administration Department should be routed through the president. Based on this assumption, resistance can be expected to accumulate. Figure 4 shows an example of $C R M$ derived from the benchmarking company of a case study.

Once the $A R M$ and $C R M$ related to the same process were established, the TRI can be calculated by Equation (4). Figure 5 shows the TRI

Total Resistance Index $(T R I)=\Sigma T_{m n}$

where $T_{m n}=A R M$ (.) $C R M$

(.) :product symbol; and $m, n:$ members of project organizational structure. 


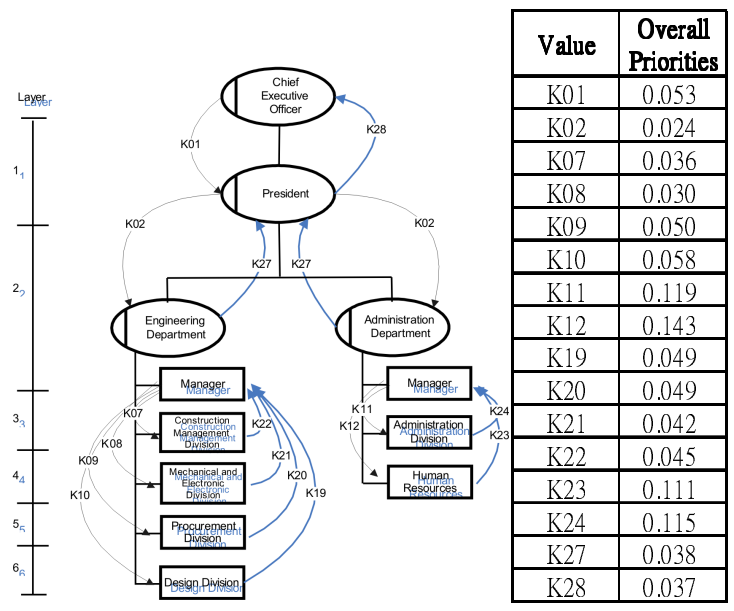

Figure 3. Communication Resistance of Procurement Process in Benchmarking Organization Structure

\begin{tabular}{|c|c|c|c|c|}
\hline \multicolumn{2}{|c|}{} & \multicolumn{3}{|c|}{ Succeding Activity Unit } \\
\cline { 2 - 5 } & $\begin{array}{c}\text { Construction } \\
\text { Management } \\
\text { Division }\end{array}$ & $\begin{array}{c}\text { Procurement } \\
\text { Division }\end{array}$ & $\begin{array}{c}\text { Administration } \\
\text { Division }\end{array}$ \\
\hline \multirow{2}{*}{$\begin{array}{c}\text { Construction } \\
\text { Management } \\
\text { Division }\end{array}$} & 0 & $\mathrm{~K} 20+\mathrm{K} 07$ & $\begin{array}{c}\mathrm{K} 24+\mathrm{K} 27+ \\
\mathrm{K} 02+\mathrm{K} 07\end{array}$ \\
\cline { 2 - 5 } & $\begin{array}{c}\text { Procurement } \\
\text { Division }\end{array}$ & $\mathrm{K} 22+\mathrm{K} 09$ & 0 & $\begin{array}{c}\mathrm{K} 24+\mathrm{K} 27+ \\
\mathrm{K} 02+\mathrm{K} 09\end{array}$ \\
\cline { 2 - 5 } 莺 & $\begin{array}{c}\text { Administration } \\
\text { Division }\end{array}$ & $\begin{array}{c}\mathrm{K} 22+\mathrm{K} 27+ \\
\mathrm{K} 02+\mathrm{K} 11\end{array}$ & $\begin{array}{c}\mathrm{K} 20+\mathrm{K} 27+ \\
\mathrm{K} 02+\mathrm{K} 11\end{array}$ & 0 \\
\hline
\end{tabular}

Figure 4. Example of CRM Derived from Figure 3

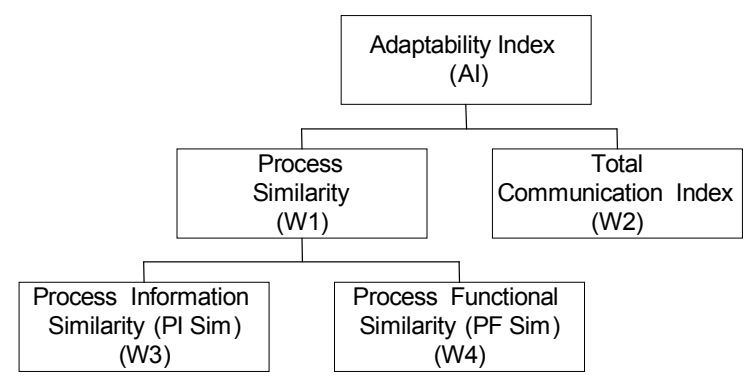

Figure 5. Hierarchy of Adaptability Index

\subsection{TCI Calculation}

After Total Resistance Index (TRI) for each bestpractice process to be performed in benchmarking company has been calculated, total communication index $(T C I)$ can be converted accordingly from the TRI to present the total degree of communication ease. Based on the TRI's concept, TCI can be presented mathematically as shown in Equation (5).

$T C I=1-T R I^{*}$

where: $0 \leq \mathrm{TCI} \leq 1$; TRI* represents normalized TRI.

The higher the communication index of best-practice process, the smoother the best-practice process can be adapted in the benchmarking company, so that the feasibility for implementing the best-practice processes might be enhanced.

\section{PROCESS ADAPTABILITY CALCULATION}

According to the evaluated process similarities and $T C I$ of best-practice processes, the adaptability index (AI) for each best-practice process can be calculated to represent the acceptance degree of each bestpractice process for benchmarking company. The higher the $A I$ is, the more suitable the process to be adapted in benchmarking company. Figure 5 shows the hierarchy of $A I$.

The $A I$ value of a best-practice process is the sum of process similarity and TCI. The relative weights (W1 W4) can be determined by managers or questionary such as Analytic Hierarchy Process (AHP).

Following to the relative weights that have been quantified and range value are set to be zero to one, the adaptability index of each best-practice company can finally be calculated. The one with the highest value is determined to be the most suitable bestpractice process to be adapted in benchmarking company.

\section{DISCUSSION}

To apply the Benchmarking to construction management process reengineering, this paper proposed an idea to determine the best-learned process from the best-practice companies. This study assumed that the most suitable process has most similar characteristics with benchmarking process resulting in its smooth performing in benchmarking 
company. Accordingly, process similarity and total communication index, were considered as two primary factors for evaluating the matching degree of the benchmarking company and best-practice companies. Additionally, this study assumed the best-practice process models had been surveyed from the best-practice companies preliminarily. However, this might be a difficult task because the best-practice companies treat their processes as confidential information. Therefore, the strategy to be permitted to retrieve the process information from best-practice companies is naturally a critical issue of benchmarking.

\section{REFERENCES}

[1] Hammer M., Champy J. (1993) Reengineering the corporation-A manifesto for business revolution, Harper Collins, New York.
[2] Cheng, M.Y., Tsai, M.H. (2003). Reengineering of Construction Management Process, J. Constr. Eng. Manage. 129(1), pp.105-114.

[3] Lee S.H., Thomas S.R., and Tucker R.L. (2005) Web-Based Benchmarking System for the Construction Industry, Journal of Construction Engineering and Management. 131(7), pp.790-798.

[4] O’Connor J.T. and Miller S.J. (1994) Constructability Programs: Method for Assessment and Benchmarking, Journal of Performance of Constructed Facilities. 8(1), pp.46-64.

[5] Scheer, A. W. (2000). ARIS-Business Process Modeling, Springer. Berlin.

[6] Cheng M.Y., Tsai M.H., (2008) Cross-Organizational Process Integration in Design-Build Team, Automation in Construction, 17(2), pp151-162.

[7] Cheng M.Y., Su C.W. and You H.Y. (2003) Optimal Project Organizational Structure for Construction Management. Journal of Construction Engineering and Management 129(1), pp.70-79. 